\title{
Spinal extradural arachnoid cyst: A rare cause of neurogenic bladder
}

Sir, Spinal extradural arachnoid cysts are a rare cause of progressive compressive myelopathy. These can be congenital or acquired as a result of trauma or inflammation. We report a rare case of a large lumbosacral extradural arachnoid cyst compressing the cauda equina resulting into the secondary neurogenic bladder.

A 45-year-old female patient presented in the OPD with the complaints of recurrent attacks of burning micturition and low back pain. The pain was mild, dull aching in nature, and was radiating to the right lower limb. Although the pain was present for the last
10-12 years, it had gradually increased in severity for the last 1-2 years. History of lumbar puncture anesthesia for cesarean section 15 years back was present. Neurological examination revealed mild right lower limb weakness. No evidence of gait abnormality or abnormal sensory levels. No bowel related symptoms were present.

Ultrasound showed bilateral mild to moderate hydronephrosis [Figures 1 and 2] with dilated both ureters up to the lower end. The left kidney was small in size with scarring at the lower pole. Urinary bladder showed thickened and trabeculated wall with a small outpouching in the right lateral wall, 
suggestive of a diverticulum [Figure 3]. Subsequently, magnetic resonance imaging (MRI) of lumbosacral spine was done on a 3-T scanner which showed a large cerebrospinal fluid (CSF) iso-intense extra-dural cyst extending from the level of L4 to lower sacrum, and causing compression over cauda equina nerve roots [Figures 4-6].

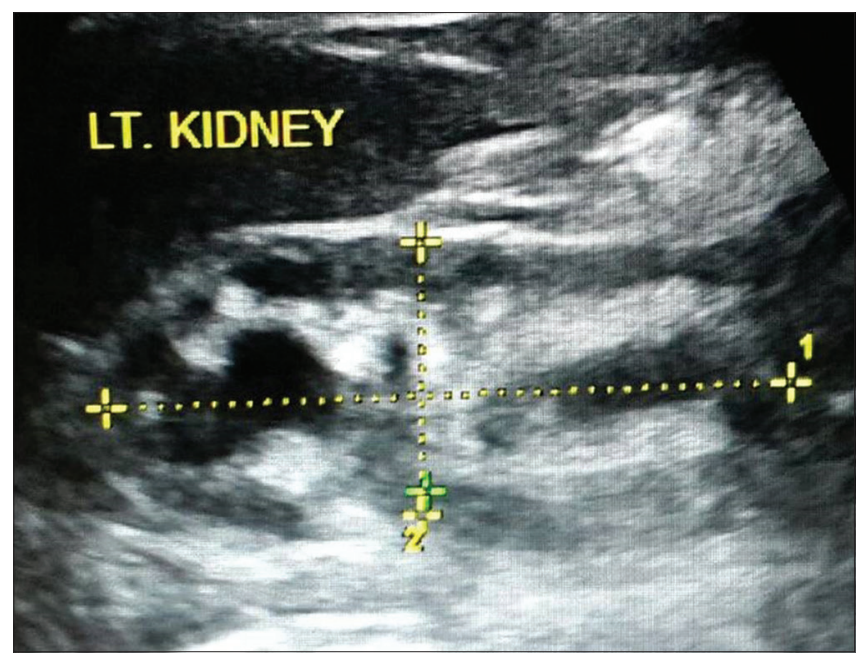

Figure 1: Left kidney shows moderate hydronephrosis with scarring at lower pole, consistent with reflux nephropathy

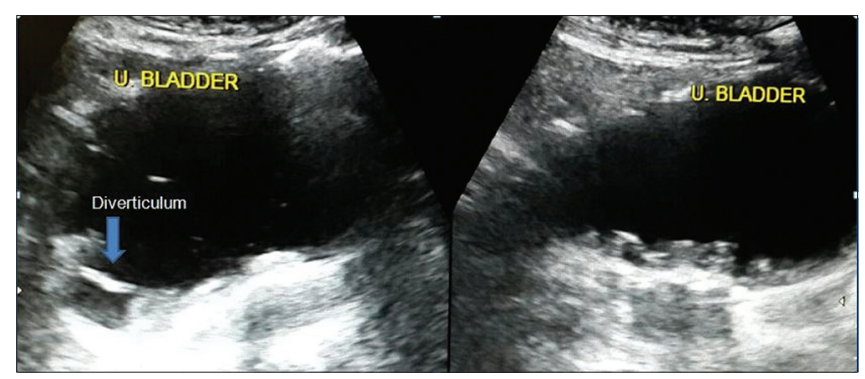

Figure 3: Axial and sagittal ultrasound image of the urinary bladder shows markedly thickened and trabeculated wall. Also noted is a small diverticulum along the right lateral wall communicating with lumen of the urinary bladder

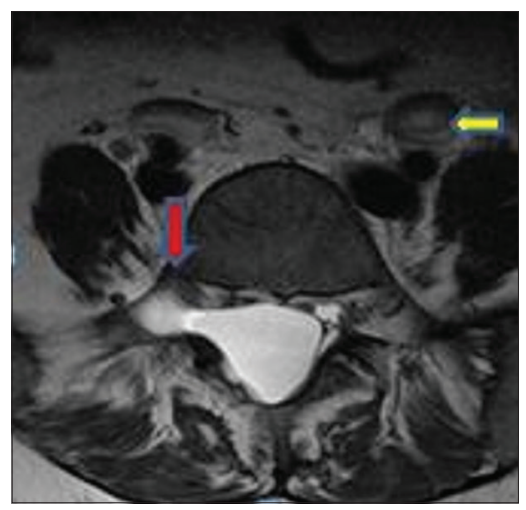

Figure 5: Axial T2-weighted imaging shows cerebrospinal fluid signal intensity lesion causing widening of spinal canal and right neural foramina with a displacement of the right exiting nerve root anteriory (red arrow). Also noted are bilateral dilated ureters (yellow arrow)
Spinal extradural arachnoid cysts are a rare cause of compressive myelopathy, located mainly in the dorsal thoracic spine. Although the etiology is still unclear,

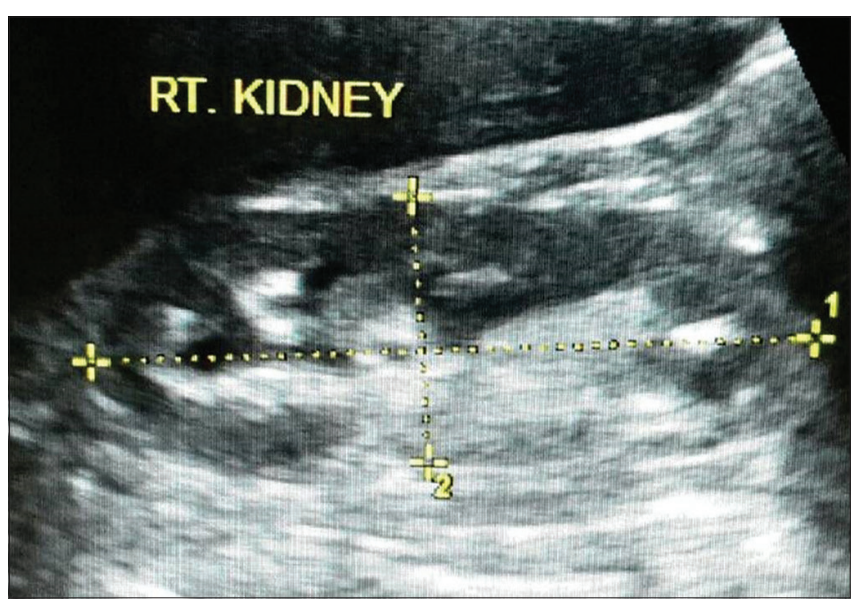

Figure 2: Right kidney shows mild hydronephrosis. No evidence of any scarring noted

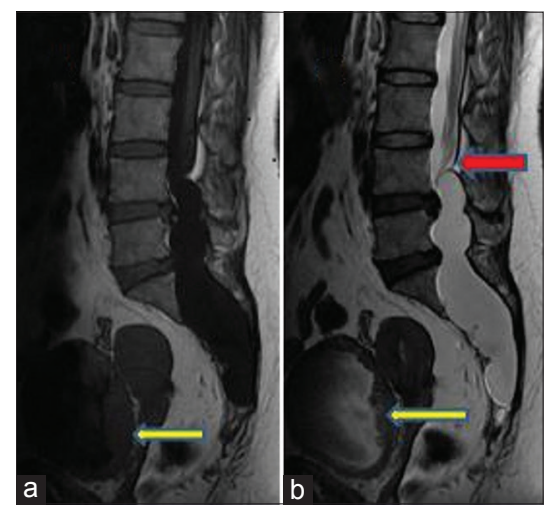

Figure 4: Sagittal TI-weighted imaging (a) and T2-weighted imaging (b) lobulated cerebrospinal fluid isointense lesion in the extradural space as evidenced by epidural fat capping at the superior pole of the lesion. The lesion is causing posterior scalloping of the lumbosacral vertebral bodies. Also noted is the mass effect over the cauda equina nerve roots (red arrow, image b) and thickened, trabeculated wall of urinary bladder (yellow arrows)

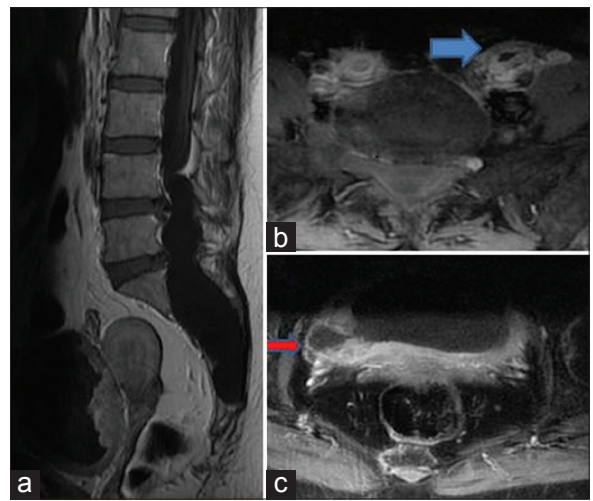

Figure 6: Postcontrast fat-suppressed TI-weighted imaging sagittal (a) and axial images ( $b$ and $c$ ), no evidence of any enhancement within the lesion. Mildly enhancing thickened wall of the urinary bladder and both ureters are noted (blue arrow, image b). Furthermore, noted is bladder diverticulum (red arrow, image c) 
these cysts have been described as type 1a Nabors spinal meningeal cysts resulting from the arachnoid mater herniation through a small dural defect. These dural defects can be congenital or acquired. Iatrogenic causes such as lumbar puncture can result in small dural tear and subsequent CSF accumulation and cyst formation. An association with Marfan syndrome has been reported in literatur. ${ }^{[1]}$

MRI may be useful for the evaluation of extradural arachnoid cysts. Findings may reveal a CSF isointense lesion in the extradural space with or without an enlarged spinal canal, epidural fat capping at the superior and inferior poles of the cyst, widened foramina, and posterior scalloping of the vertebral bodies. Computed tomography-myelography is helpful in identifying the presence of the communicating tract between the cyst and the thecal sac as seen in Type 1 meningeal cysts. ${ }^{[2]}$ CSF flow analysis using cine MRI may show communication of the cyst with CSF space.

The main differential considerations are giant Tarlov cyst, epidermoid cysts, or rarely a cystic schwannomas. Features such as homogeneous CSF signal intensity, communication with the thecal subarachnoid space, absence of any contrast enhancement in the wall, or within the cyst may be helpful in diagnosing extradural arachnoid cyst.

Conservative treatment is recommended for asymptomatic patients. In patients symptomatic cases en bloc excision of the cyst, followed by obliteration of the communicating pedicle, and complete repair of the dural defect is done. ${ }^{[3]}$

\section{Financial support and sponsorship}

Nil.

\section{Conflicts of interest}

There are no conflicts of interest.

Rajendra V. Phadke, Vivek Agarwal, Suprava Naik

Department of Radiology, SGPGIMS, Lucknow, Uttar Pradesh, India

Address for correspondence: Dr. Vivek Agarwal,

Department of Radiology, SGPGIMS, Lucknow,Uttar Pradesh, India. E-mail: vivekagarwal0004@gmail.com

\section{References}

1. Lee CH, Hyun SJ, Kim KJ, Jahng TA, Kim HJ. What is a reasonable surgical procedure for spinal extradural arachnoid cysts: Is cyst removal mandatory? Eight consecutive cases and a review of the literature. Acta Neurochir (Wien) 2012;154:1219-27.

2. Sangala JR, Uribe JS, Park P, Martinez C, Vale FL. Nerve root prolapse into a spinal arachnoid cyst - An unusual cause of radiculopathy. Clin Neurol Neurosurg 2009;111:460-4.

3. Ersahin Y, Yildizhan A, Seber N. Spinal extradural arachnoid cyst. Childs Nerv Syst 1993;9:250-2.

This is an open access article distributed under the terms of the Creative Commons Attribution-NonCommercial-ShareAlike 3.0 License, which allows others to remix, tweak, and build upon the work non-commercially, as long as the author is credited and the new creations are licensed under the identical terms.

\begin{tabular}{|l|l|}
\hline \multicolumn{2}{|c|}{ Access this article online } \\
\hline Quick Response Code: & Website: \\
\hline & www.ruralneuropractice.com \\
\hline & \\
\hline
\end{tabular}

How to cite this article: Phadke RV, Agarwal V, Naik S. Spinal extradural arachnoid cyst: A rare cause of neurogenic bladder. J Neurosci Rural Pract 2016;7:467-9. 